\title{
Ten years of the neonatal respiratory extracorporeal membrane oxygenation program in an Argentinian public hospital
}

\author{
Gisela L. Salas, M.D. ${ }^{a}$, María S. Arbio, M.D. ${ }^{a}$, Sonia B. Rodas, B.S. ${ }^{a}$, \\ Eduardo D. Dominguez, M.D. ${ }^{a}$, Gustavo S. Goldsmit, M.D. ${ }^{a}$ and Diana M. Fariña, M.D. ${ }^{a}$
}

\begin{abstract}
Extracorporeal membrane oxygenation (ECMO) is a highly invasive rescue treatment for criticallyill patients. The objective of the study was to show the outcomes of patients treated with ECMO in the neonatal intensive care unit of Hospital de Pediatría Juan P. Garrahan in the first 10 years of the program, and to analyze the risk factors associated with mortality on ECMO.

Method. Descriptive, retrospective study with risk factor analysis. All patients treated with ECMO between April 2008 and February 2019 were included.

Results. A total of 77 patients were included: 72 neonates and 5 infants younger than 1 year. Patients' median age at admission was 2 days (1-150); weight: $3200 \mathrm{~g} \pm 730 \mathrm{~g}$; gestational age: 37.5 weeks $\pm 4.2 ; 53 \%$ were males; and $50 \%$ had been born by C-section. The most common diagnoses included congenital diaphragmatic hernia and meconium aspiration syndrome. Fifty-six patients $(73 \%)$ survived ECMO; of them, $17(30 \%)$ died before discharge. The outcome measures associated with mortality on ECMO were central nervous system hemorrhage $(p<$ $0.01)$, hemodiafiltration requirement $(p<0.01)$, inotrope requirement during ECMO $(p<0.01)$, and presence of hemorrhage not affecting the central nervous system $(p<0.01)$.

Conclusions. This study describes the outcomes of the first 10 years of the neonatal respiratory ECMO program. The onset of complications increased mortality during ECMO.

Key words: extracorporeal membrane oxygenation,
\end{abstract} newborn infant, respiratory failure.

a. Neonatal Intensive Care Unit, Hospital de Pediatría SAMIC "Prof. Dr. Juan. P. Garrahan," Autonomous City of Buenos Aires, Argentina.

E-mail address:

Gisela L. Salas, M.D.:

gsalasenator@gmail.com

Funding:

None.

Conflict of interest:

None.

Received: 6-23-2019

Accepted: 12-26-2019

To cite: Salas GL, Arbio MS, Rodas SB, Domínguez ED, etal. Ten years of theneonatal respiratory extracorporeal membrane oxygenation program in an Argentinian publichospital. Arch Argent Pediatr 2020;118(4):258-264.

\section{INTRODUCTION}

Extracorporeal membrane oxygenation (ECMO) is a procedure to provide cardiopulmonary support to patients with respiratory and / or heart failure, a mortality risk of more than $80 \%$, and in whom an advanced conventional therapy has been unsuccessful. ECMO is a highly invasive and costly rescue treatment. ${ }^{1-3}$

It allows the heart and lungs to rest until recovery. This is achieved through an adequate oxygen delivery to the organs; it minimizes the damage caused by mechanical ventilation (MV) and avoids the use of high doses of inotropes.

There are two ECMO modalities: veno-arterial (VA ECMO) and venovenous (VV ECMO). VA ECMO provides both heart and respiratory support, whereas VV ECMO, only respiratory support. The indication of one or the other will mainly depend on the patient's diagnosis and hemodynamic status. It has been reported that VV ECMO causes less complications than VA ECMO, especially in relation to the central nervous system (CNS). ${ }^{4}$

Although it is a highly invasive treatment with potential lifethreatening complications, its use in the neonatal unit has a strong impact on the survival of severelyill patients. ${ }^{5}$ Results depend mainly on the admission diagnosis and the duration of ECMO support required by the patient. ${ }^{6}$ The diagnoses that often require ECMO at the neonatal unit include primary pulmonary hypertension of the newborn (PPHN), meconium aspiration syndrome (MAS), congenital diaphragmatic hernia $(\mathrm{CDH})$, viral and bacterial 
pneumonia, sepsis, arrhythmias, etc. ${ }^{6,7}$

The first publications of successful ECMO support were made by $\mathrm{Hill}^{8}$ and then by Barlett ${ }^{9}$ in 1976. These were followed by several publications that described cases and compared them with historical controls that demonstrated a progressive increase in survival. ${ }^{10,11}$ In the 1980s, prospective, controlled trials helped to disseminate this technique. ${ }^{12,13}$ In 1996, the UK Collaborative ECMO Trial was published, which confirmed that ECMO significantly reduced mortality among critically-ill neonates compared with conventional treatment (mortality of $32 \%$ versus $59 \%$; relative risk [RR]: $0.55 ; 95 \%$ confidence interval [CI]: 0.36-0.8). ${ }^{14}$ The outcomes of long-term follow-up were subsequently published and found to be promising. ${ }^{15}$

The ECMO Program implemented at the neonatal intensive care unit (NICU) of Hospital de Pediatría Juan P. Garrahan started in 1998 with multidisciplinary theoretical and practical workshops and ECMO procedures in experimental animals (Landrace breed pigs). ${ }^{16}$ After an intensive training phase, the clinical phase was launched. In 2008, the first neonatal patient was treated with ECMO at the NICU. The ECMO Program of Hospital Garrahan provides ECMO in three different units: the NICU, the pediatric intensive care unit, and the cardiovascular care unit. To date, more than 180 patients have been admitted to the program. Since 2013, the hospital has become an active member of the Extracorporeal Life Support Organization (ELSO). It offers training and coaching to team members, including highfidelity simulation workshops.
The objective of this study was to show the results of patients treated with ECMO in the NICU in the first 10 years of the program, and to analyze the risk factors associated with mortality on ECMO.

\section{MATERIAL AND METHODS}

This was a descriptive, retrospective study with risk factor analysis. All patients treated with ECMO between April 2008 and February 2019 in the Department of Neonatology of Hospital de Pediatría Juan P. Garrahan were included. Table 1 describes the inclusion criteria for ECMO treatment, which were based on the ELSO treatment guidelines. ${ }^{17}$

In all cases, parents were asked to sign the informed consent for the anonymous use of data. The study was approved by the hospital's Ethics Committee.

ECMO Program structure: The ECMO team was made up of a medical coordinator and a nursing coordinator, 18 neonatologists, and 25 neonatal nurses. In addition, cardiovascular surgeons and members of the Departments of Hematology, Hemotherapy, Cardiology, Pharmacy and Diagnostic Imaging participated. The decision to place a patient on, or withdraw them from ECMO was agreed upon between the ECMO team and the patient's medical team. In all cases, the informed consent for admission was obtained from the parents. ${ }^{16}$

Patient management protocol during ECMO: Patients were placed in a radiant warmer with a lifting system, in the dorsal recumbent position and with their head towards the feet of the warmer for neck vessel cannulation. A multiparametric monitor was used to measure invasive

TABLE 1. Inclusion criteria for neonatal respiratory extracorporeal membrane oxygenation

\section{Inclusion criteria}

Gestational age $>34$ weeks

- Ventilatory support for no more than 14 days (relative criterion).

- Absence of severe conditions: chromosomal abnormalities, severe anatomical malformations or malformation syndromes.

- Absence of PVH/IVH of grade II or higher. No evidence of severe brain damage.

- Absence of massive bleeding.

- Presence of severe respiratory failure:

- $\quad \mathrm{OI}^{*}>40$, in 3 arterial measurements in a 3-5 h period (OI $=\mathrm{MAP} \times \mathrm{FiO}_{2} /$ post-ductal PaO2).

- Severe collapse with $\mathrm{PaO}_{2}<40$ Torr, with no response to maximum therapy (high frequency ventilation, inhaled nitric oxide administration).

- Collapse events, 3 or more in 12 hours and that require resuscitation with positive pressure.

- Severe heart dysfunction, unresponsive to conventional therapy:

- Echocardiogram showing severe ventricular dysfunction with maximum vasoactive support: dopamine $\geq 20 \mu \mathrm{g} / \mathrm{kg} / \mathrm{min}$; epinephrine $\geq 0.5 \mu \mathrm{g} / \mathrm{kg} / \mathrm{min}$; dobutamine $\geq 20 \mu \mathrm{g} / \mathrm{kg} / \mathrm{min} ; \mathrm{milrinone}=0.8 \mu \mathrm{g} / \mathrm{kg} / \mathrm{min}$. - Continuous volume expansion requirement. Inclusion criteria

* OI: oxygenation index; MAP (mean airway pressure) $x \mathrm{FiO}_{2}$ (fraction of inspired oxygen)/ partial pressure of oxygen; $\mathrm{PVH} / \mathrm{IVH}$ : periventricular/intraventricular hemorrhage. 
blood pressure and central body temperature, and record pulse oximetry and continuous electrocardiographic data. A transcutaneous monitor measurement of partial pressure of carbon dioxide, regional saturation of the parenchyma with near-infrared spectroscopy and a continuous monitoring of brain function with an amplitude-integrated electroencephalography (aEEG) were added.

The circuit was flushed sequentially with normal saline solution, albumin, and blood. The vessels, right internal jugular vein, and right carotid artery were cannulated by the Cardiovascular Surgery team. A chest X-ray and an echocardiogram were done to confirm cannula position.

Anticoagulation was achieved by continuous infusion of heparin sodium. Anticoagulation was initially monitored based on the activated coagulation time (ACT) (Medtronic ${ }^{\circledR}$ ) and hemostasis controls: anti-Xa factor, antithrombin, D-dimer, activated partial thromboplastin time (aPTT), prothrombin time (PT), fibrinogen, and platelet count. An antithrombin concentrate, tranexamic acid, and blood products were also administered, as needed and based on the ECMO transfusion management protocol. An echocardiogram, brain and abdominal ultrasounds, lab tests, and blood cultures were done on a daily basis.

ECMO equipment: An occlusive roller pump (Century and/or Cobe ${ }^{\circledR}$ ), an $0.8 \mathrm{~m}^{2}$ membrane oxygenator (Avecor ${ }^{\circledR}$, Euroset $^{\circledR}$, Medos $^{\circledR}$, Quadrox $^{\circledR}$ ), and Super Tygon tubing with $1 / 4^{\prime \prime}$ (a quarter of an inch) internal diameter and $1 / 16^{\prime \prime}$ wall thickness $\left(\right.$ Medos $^{\circledR}$ and Medtronic ${ }^{\circledR}$ ) were used. The circuit included a mixed venous oxygen saturation $\left(\mathrm{SvO}_{2}\right)$ and hematocrit monitor (3M-CDI- $\left.100^{\circledR}\right)$, a flow monitor and bubble detector (Transonic ${ }^{\circledR}$ ), and a pre- and post-membrane pressure monitor (model 66000, Medtronic $\left.{ }^{\circledR}\right)$. An Argimed ${ }^{\circledR}$ hemofilter system was used.

Study outcome measures: The following demographic outcome measures were analyzed: sex, gestational age (GA), Apgar score, mode of delivery (vaginal or C-section), days of life and weight at the time of ECMO initiation, diagnosis at admission, and length of ECMO treatment in days. Outcome variables included survival after ECMO (patients who were alive 72 hours after ECMO support had finished) and survival at discharge. The following complications were reported: disseminated intravascular coagulation (DIC) and renal failure (defined as the need for hemofiltration / hemodiafiltration during ECMO). The presence of CNS hemorrhage was defined as severe hemorrhage causing treatment interruption, and hemorrhagic complications not affecting the CNS were grouped into pulmonary, abdominal and / or cannula site bleeding (nonCNS hemorrhage), inotrope requirement during $\mathrm{ECMO}$, presence of hypertension (HTN) requiring antihypertensive drugs, ${ }^{18}$ arrhythmias, cardiac tamponade requiring pericardial drainage, and cardiac stun, defined as an electromechanical dissociation of the left ventricle. Mechanical complications included oxygenator breakage or malfunctioning and/or circuit changes. Metabolic complications were also recorded: presence of hypoglycemia (blood glucose $<50 \mathrm{mg} / \mathrm{dL}$ ), hyperglycemia (blood glucose $>150 \mathrm{mg} / \mathrm{dL}$ ), hyponatremia (blood sodium $<130 \mathrm{mEq} / \mathrm{L}$ ), hypernatremia (blood sodium $>150 \mathrm{mEq} / \mathrm{L}$ ), alkalosis (blood $\mathrm{pH}>7.4$ ) and / or acidosis (blood $\mathrm{pH}<7.35$ ) during ECMO.

Statistical analysis: All outcome measures were summarized using descriptive statistics of central tendency, position, and dispersion. Numerical outcome measures were compared using a Wilcoxon non-parametric test or $t$ test, based on their distribution; whereas categorical outcome measures were analyzed using the $\chi^{2}$ test. The adjusted odds ratio (aOR) and its corresponding $95 \%$ CI were estimated. Risk outcome measures were adjusted using a logistic regression model. The post-estimation test of Hosmer-Lemeshow was used to assess the model's adjustment capacity and discrimination power. A value of $p<0.05 \mathrm{w}$ as considered statistically significant. The statistical analysis was performed with the STATA SE 12.0 software (StataCorp LP, USA).

\section{RESULTS}

Seventy-seven patients were included in the study: 72 neonates and 5 infants younger than 1 year. All patients were treated with VA ECMO. Table 2 describes the demographic characteristics of the population. The most common diagnosis for admission to ECMO were $\mathrm{CDH}$ in 49 patients $(64 \%)$, primary pulmonary hypertension in 10 , MAS in 7, bronchiolitis in 3 (1 patient with H1N1 influenza pneumonia and 2 with respiratory syncytial virus), Bordetella pertussis pneumonia in 4 , and bacterial sepsis in 4 .

Among the 21 patients who died on ECMO, in 7 it had been decided to withdraw it due to a poor clinical course or irreversible complications. Fifty- 
six patients $(73 \%)$ survived ECMO treatment, and $39(51 \%)$ survived upon hospital discharge (Figure 1).

The comparison of demographic outcome measures did not find significant differences between the group of survivors and that of deceased patients. However, the onset of complications showed statistically significant differences between both groups (Table 3).

Predictor outcome measures were adjusted for the multivariate analysis, which showed that the presence of renal failure (aOR: 22.7; $95 \%$ CI: 1.22420), hemorrhagic complications not affecting

TABLE 2. Demographic characteristics of the population

\begin{tabular}{lc}
\hline & N: 77 \\
\hline Male sex & $41(53 \%)$ \\
C-section & $38(50 \%)$ \\
Weight $^{*}$ & $3200 \mathrm{~g}( \pm 650 \mathrm{~g})$ \\
Gestational age $^{*}$ & 37.6 weeks (SD: 3.5) \\
Apgar score at 5** $^{\prime *}$ & $8( \pm 2)$ \\
Age at admission (days) $^{* *}$ & $2(1-150)$ \\
Days of ECMO $^{* *}$ & $5(1-41)$ \\
\hline
\end{tabular}

Values are expressed as percentage for categorical outcome measures, * mean and standard deviation (SD) and

${ }^{* *}$ median and interquartile range.

ECMO: extracorporeal membrane oxygenation. the CNS (aOR: 16.7; $95 \%$ CI: 2.6-105), CNS hemorrhage (aOR: 4.09; $95 \%$ CI: 1.65-10.12), and inotrope requirement during ECMO (aOR: 10.03; $95 \%$ CI: 1.5-65.4) were risk factors for mortality $(p \leq 0.01)$. Broader $95 \%$ CIs were observed due to the infrequent onset of analyzed events, except for the CNS hemorrhage outcome measure. This logistic regression model was robust and had an adequate discrimination power, with a $p$ value $=0.33$ in the Hosmer-Lemeshow test, and an area under the curve $=0.95$ (Table 4).

\section{DISCUSSION}

In this study, patients with $\mathrm{CDH}$ who required ECMO had a better survival 72 hours after ECMO compared with survival at discharge. Mortality 72 hours after treatment is considered rather related to ECMO outcomes; however, mortality at discharge may be highly related to the underlying condition.

Our results are consistent with international statistics. Based on international registries, mortality due to $\mathrm{CDH}$ requiring ECMO has remained stable in the past 20 years in spite of technological advances. ${ }^{18} \mathrm{ECMO}$ appears to be a useful treatment to stabilize patients with $\mathrm{CDH}$ in the preoperative period. Therefore, being able to differentiate patients with irreversible pulmonary

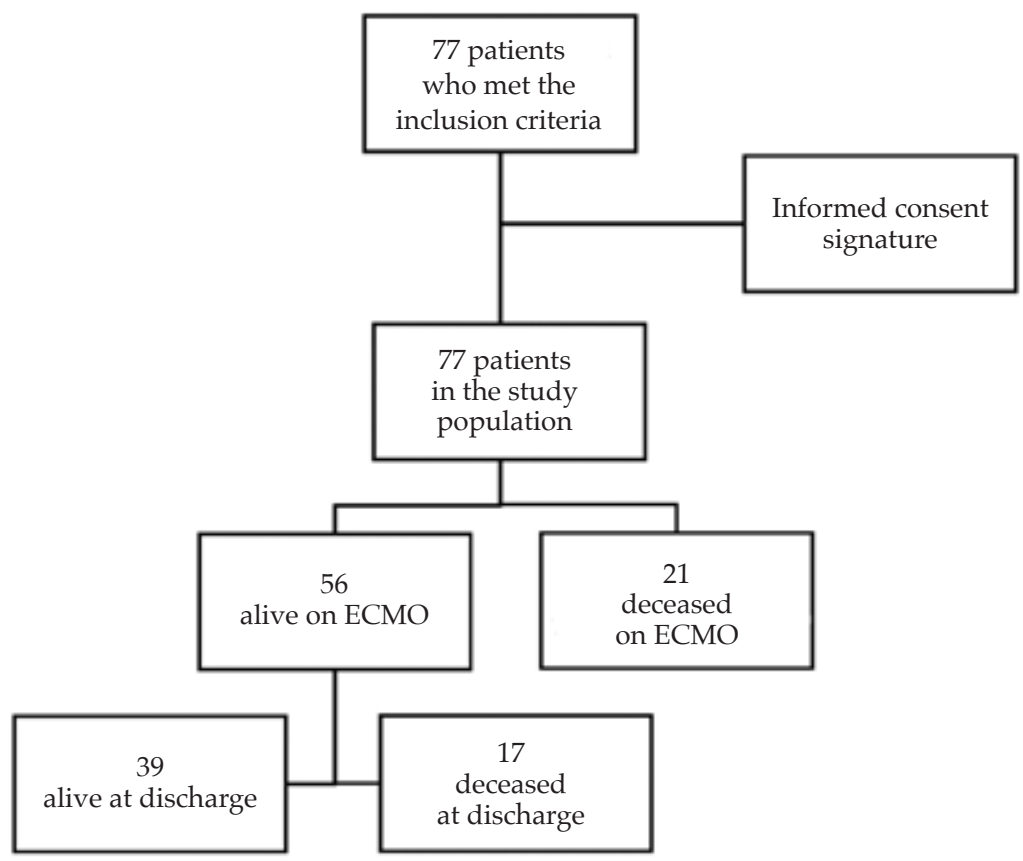

ECMO: extracorporeal membrane oxygenation. 
hypoplasia in this population will allow a more rational use of ECMO. ${ }^{19,20}$

Patients diagnosed with respiratory failure secondary to MAS and PPHN on ECMO have a better survival according to international reports, close to $95 \%$. On the other end, patients with $\mathrm{CDH}$ have the lowest survival of ECMO due to respiratory conditions in the neonatal period. It is worth noting that, with the advances in neonatal intensive care, admission to ECMO of patients with MAS and PPHN has decreased in recent years. $\mathrm{CDH}$ has become the main reason for placing patients on ECMO at the NICU. ${ }^{21}$

The onset of CNS hemorrhage was an independent risk factor for mortality in this population. In a prospective, cohort study of 514 neonatal and pediatric patients, with an overall survival of $55 \%$, brain hemorrhage was diagnosed in $16 \% .{ }^{22}$ In our study, the presence of such complication accounted for $25 \%$. In

TABLE 3. Comparison of demographic outcome measures and complications based on mortality

\begin{tabular}{|c|c|c|c|}
\hline & Live, $n=56$ & Deceased, $n=21$ & $p$ \\
\hline GA (weeks)* & $37.7( \pm 4.14)$ & $37.3( \pm 1.2)$ & 0.7 \\
\hline Male sex & $30 / 56$ & $11 / 21$ & 0.92 \\
\hline Weight $(\mathrm{g})^{*}$ & $3250( \pm 676)$ & $3100( \pm 550)$ & 0.34 \\
\hline Apgar score at $5 \mathrm{~min}^{*}$ & $7.7( \pm 1.6)$ & $8.1( \pm 1.7)$ & 0.34 \\
\hline Mode of delivery: C-section** & $27 / 56$ & $12 / 21$ & 0.48 \\
\hline Age (days) ${ }^{* *}$ & 8.5 & 8.9 & 0.9 \\
\hline Days of ECMO ${ }^{* *}$ & $7.46( \pm 7.2)$ & $5.3( \pm 5.3)$ & 0.22 \\
\hline \multicolumn{4}{|l|}{ Diagnoses: } \\
\hline $\begin{array}{l}\text { - CDH } \\
\text { - PPHN } \\
\text { - MAS } \\
- \text { Bronchiolitis } \\
- \text { Sepsis } \\
- \text { Bordetella pertussis }\end{array}$ & $\begin{array}{l}35 / 49 \\
8 / 10 \\
7 / 7 \\
2 / 3 \\
2 / 4 \\
2 / 4\end{array}$ & $\begin{array}{c}14 / 49 \\
2 / 10 \\
0 \\
1 / 3 \\
2 / 4 \\
2 / 4\end{array}$ & 0.61 \\
\hline Renal failure & $1 / 3$ & $2 / 3$ & $<0.01$ \\
\hline Non-CNS hemorrhage & $3 / 11$ & $8 / 11$ & $<0.01$ \\
\hline CNS hemorrhage & $8 / 21$ & $13 / 21$ & $<0.01$ \\
\hline Inotrope requirement & $3 / 12$ & $9 / 12$ & $<0.01$ \\
\hline Mechanical complications & $12 / 15$ & $3 / 15$ & 0.46 \\
\hline DIC & $5 / 11$ & $6 / 11$ & 0.28 \\
\hline HTN & $7 / 11$ & $4 / 11$ & 0.46 \\
\hline Arrhythmias & $2 / 2$ & 0 & 0.38 \\
\hline Cardiac stun & $1 / 2$ & $1 / 2$ & 0.46 \\
\hline Cardiac tamponade & $6 / 9$ & $3 / 9$ & 0.16 \\
\hline
\end{tabular}

Results are expressed as fractions: number/total patients. * Mean and standard deviation (SD).

** Median and interquartile range (IQR).

GA: gestational age; ECMO: extracorporeal membrane oxygenation; CDH: congenital diaphragmatic hernia;

PPHN: primary pulmonary hypertension of the newborn; MAS: meconium aspiration syndrome; CNS: central nervous system;

DIC: disseminated intravascular coagulation; HTN: hypertension.

TABLE 4. Multivariate analysis of complications that were statistically significant in both groups

\begin{tabular}{lccccc}
\hline Complications & Live, $\mathbf{n}=\mathbf{5 6}$ & Deceased, $\mathbf{n}=\mathbf{2 1}$ & $p$ & aOR & $\mathbf{9 5} \% \mathbf{C I}$ \\
\hline Renal failure & 1 & 2 & $<0.01$ & 22.7 & {$[1.22-420]$} \\
Non-CNS hemorrhage & 3 & 8 & $<0.01$ & 16.7 & {$[2.6-105]$} \\
CNS hemorrhage & 8 & 13 & $<0.01$ & 4.09 & {$[1.65-10.12]$} \\
Inotrope requirement & 3 & 9 & $<0.01$ & 10.03 & {$[1.5-65.4]$} \\
\hline
\end{tabular}

aOR: adjusted odds ratio; CI: confidence interval; CNS: central nervous system.

Hosmer-Lemeshow AUC: 0.95, $\mathrm{p}=0.33$. aOR: adjusted odds ratio; CI: confidence interval; CNS: central nervous system. 
the initial program period, the incidence of this complication increased, but it has decreased in the past 2 years, consistent with the changes introduced in the anticoagulation protocol.

The incidence of non-CNS hemorrhage (pulmonary, abdominal, and cannula site bleeding) was $16 \%$, i.e., lower than that reported by the ELSO. ${ }^{23}$ However, the presence of a complication was a risk factor for mortality in this population $(p \leq 0.01)$.

Hemorrhagic complications among patients treated with ECMO lead to significant morbidity and mortality. ${ }^{24}$ They may be prevented with a careful titration of anticoagulation therapy, which helps to minimize their onset. ${ }^{1,25}$

The need for dialysis techniques (hemodiafiltration or hemofiltration) during ECMO depends mostly on the presence of renal failure, oliguria or anuria and/or fluid overload. In our study, $6.5 \%$ of studied patients required hemodiafiltration. Such incidence was lower than that reported by the ELSO $(15.7 \%){ }^{26,27}$ The presence of renal failure requiring dialysis on ECMO increased the risk for mortality in this population.

Other mortality-associated outcome measure in this study was inotrope requirement during ECMO support. ECMO offers partial cardiac support. It has been estimated that $80 \%$ of the patient's cardiac output is provided by ECMO, thus allowing the patient's native cardiac output to provide coronary artery irrigation and a fast improvement of heart function. ${ }^{28}$ During VA ECMO initiation, inotropes and vasopressors are expected to be interrupted. If this is not possible, the risk for mortality on ECMO is higher.

Although this is an unprecedented report in Argentina due to the number of neonatal patients included, the complex treatment used and its development in a public hospital, a weakness of this study was that it reported outcomes from a single site and the limited number of patients and complications. The analysis of such first cases, the incidence of difficulties, and their relation to outcomes will allow to chart a course toward ongoing improvements. They will aim at reducing the number of complications and introducing new technologies in order to minimize morbidity and mortality in the long term among patients treated with ECMO.

\section{CONCLUSION}

This study describes the outcomes of the first 10 years of the neonatal respiratory ECMO program, which were similar to those reported internationally. The onset of complications during the procedure increased mortality.

\section{REFERENCES}

1. Van Ommen C, Neunert C, Chitlur M. Neonatal ECMO. Front Med (Lausanne). 2018; 5:289.

2. Raman L, Dalton HJ. Year in Review 2015: Extracorporeal Membrane Oxygenation. Respir Care. 2016; 61(7):986-91.

3. Petrou S, Bischof M, Bennett C, Elbourne D, et al. Costeffectiveness of neonatal extracorporeal membrane oxygenation based on 7-year results from the United Kingdom Collaborative ECMO Trial. Pediatrics. 2006; 117(5):1640-9.

4. Delaplain PT, Jancelewicz T, Di Nardo M, Zhang L, et al. Management preferences in ECMO mode for congenital diaphragmatic hernia. J Pediatr Surg. 2019; 54(5):903-8.

5. Kattan J, Godoy L, Zavala A, Faunes M, et al. Improvement of survival in infants with congenital diaphragmatichernia in recent years: effect of ECMO availability and associated factors. Pediatr Surg Int. 2010; 26(7):671-6.

6. Smith M, Vukomanovic A, Brodie D, Thiagarajan R, et al. Duration of veno-arterial extracorporeal life support (VA ECMO) and outcome: an analysis of the Extracorporeal Life Support Organization (ELSO) registry. Crit Care. 2017; 21(1):45.

7. Fletcher K, Chapman R, Keene S. An overview of medical ECMO for neonates. Semin Perinatol. 2018; 42(2):68-79.

8. Hill JD, De Leva MR, Fallat RJ, Bramson ML, et al. Acute respiratory insufficiency. Treatment with prolonged extracorporeal oxygenation. J Thorac Cardiovasc Surg. 1972; 64(4):551-62.

9. Bartlett RH, Gazzaniga AB, Jefferies MR, Huxtable RF, et al. Extracorporeal membrane oxygenation (ECMO) cardiopulmonary support in infancy. Trans Am Soc Artif Intern Organs. 1976; 22(1):80-93.

10. Bartlett RH, Andrews AF, Toomasian JM, Haiduc NJ, et al. Extracorporeal membrane oxygenation for newborn respiratory failure: forty-five cases. Surgery. 1982; 92(2):425-33.

11. Short BL, Miller MK, Anderson KD. Extracorporeal membrane oxygenation in the management of respiratory failure in the newborn. Clin Perinatol. 1987; 14(3):737-48.

12. Bartlett RH, Roloff DW, Cornell RG, Andrews AF, et al. Extracorporeal circulation in neonatal respiratory failure: a prospective randomized study. Pediatrics. 1985; 76(4): 479-87.

13. O'Rourke PP, Crone RK, Vacanti JP, Ware JP, et al. Extracorporeal membrane oxygenation and conventional medical therapy in neonates with persistent pulmonary hypertension of the newborn: a prospective randomized study. Pediatrics. 1989; 84(6):957-63.

14. UK Collaborative ECMO Trial Group. UK collaborative randomized trial of neonatal extracorporeal membrane oxygenation. Lancet 1996; 348(9020):75-82.

15. Bennet C, Johnson A, Field D, Elbourne D; UK Collaborative ECMO Trial Group. UK Collaborative randomised trial of neonatal extracorporeal membrane oxigenation: follow up to age 4 years. Lancet. 2001; 357(9262):1094-6.

16. Domínguez ED, Salas GL, Valdés M, Rubio C, et al. Oxigenación por Membrana Extracorpórea (ECMO): Experiencia en una Unidad de Cuidado Intensivo Neonatal. Arch Argent Pediatr. 2012; 110(5):404-11.

17. Gray B, Rintoul N. Guidelines for Neonatal Respiratory Failure. Extracorporeal Life Organization, Version 1.4. Ann Arbor: ELSO; 2017. [Accessed on: December 27 ${ }^{\text {th }}$, 
2019]. Available at: https://www.elso.org/Portals/0/ ELSOGuidelinesNeonatalRespiratoryFailurev1_4.pdf.

18. Kays DW. ECMO in CDH: Is there a role? Semin Pediatr Surg. 2017; 26(3):166-70.

19. McHoney M, Hammond P. Role of ECMO in congenital diaphragmatic hernia. Arch Dis Child Fetal Neonatal Ed. 2018; 103(2):F178-81.

20. Rambaud J, Guilbert J, Guellec I, Jean S, et al. Place de $1 \square$ assistence respiratoire et circulatoire extracorporelle de courte durée (ECMO), post-cardiotomie exclue, dans la prise en charge des défaillances graves du nouveau-né et de l'enfant. Arch Pediatr. 2017; 24(6):578-86.

21. Mugford M,Elbourne D, FieldD. Extracorporeal membrane oxygenation for severe respiratory failure in newborn infants. Cochrane Database Syst Rev. 2008; (3):CD001340.

22. Dalton HJ, Reeder R, Garcia-Filion P, Holubkov R, et al. Factors associated with bleeding and thrombosis in children receiving extracorporeal membrane oxygenation. Am J Respir Crit Care Med. 2017; 196:762-71.
23. Brogan T, Lequier L, Lorusso R, McLaren G, et al (eds.). Extracorporeal Life Support: The Elso Red Book. $5^{\text {th }}$ ed. Ann Arbor, MI: ELSO; 2019.

24. Kamdar A, RintoulN, Raffini L. Anticoagulation in neonatal ECMO. Semin Perinatol. 2018; 42(2):122-8.

25. Cashen K, Reeder R, Dalton HJ, Berg RA, et al. Functional status of neonatal and pediatric patients after extracorporeal membrane oxygenation. Pediatr Crit Care Med. 2017; 18(6):561-70.

26. Thiagarajan RR, Barbaro RP, Rycus PT, Mcmullan DM, et al. Extracorporeal Life Support Organization Registry International Report 2016. ASAIO J. 2017; 63(1):60-7.

27. Mahmood B, Newton D, Pallotto EK. Current trends in neonatal ECMO. Semin Perinatol. 2018; 42(2):80-8.

28. Sewell EK, Piazza AJ, Davis J, Heard ML, et al. Inotrope Needs in Neonates Requiring Extracorporeal Membrane Oxygenation for Respiratory Failure. J Pediatr. 2019; 214:128-33. 